\title{
Welsh Springer Spaniel
}

National Cancer Institute

\section{Source}

National Cancer Institute. Welsh Springer Spaniel. NCI Thesaurus. Code C53887.

The Welsh Springer Spaniel is a compact, medium-sized dog with a medium-length, dark red and white coat that is straight or slightly wavy with feathering on the chest,

undersides, legs, and tail. The long ish pendant ears are fringed with hair, somewhat like a setter's. Height: 16-19 inches (41-48 cm.) Weight: 35-45 pounds (16-20 kg.) 